\title{
Augmented Reality as Cyber-Innovation in STEM Education
}

\author{
Dr. Tahar Messadi ${ }^{1}$, Dr. Winifred E. Newman², Dr. David Fredrick ${ }^{1}$, Chloe Costello ${ }^{1}$, Keenan Cole ${ }^{1}$ \\ ${ }^{1}$ School of Architecture, University of Arkansas, Fayetteville, United States \\ ${ }^{2}$ Clemson University, School of Architecture, Clemson, United States \\ Email: elyssen@clemson.edu
}

\begin{abstract}
This paper presents the second phase of an NSF-sponsored research project in classroom innovation using augmented reality (AR) to enhance STEM education developed at the University of Arkansas. The discussion centers on the design and development of AR technology and its application for use by engineering and architecture students in understanding complex data in sustainability. Exposing students to advances in digital modeling, data visualization and performative software prepares them for new pathways of decision-making in the AEC professions. Recent research shows technology mediated learning environments (interacting with computer-based tools) enhance learning. Augmented reality (AR) or the ability to augment the real-world environment with computer-generated information brings a new dimension to learning and design using multiple data streams. Our research addresses first, the opportunities and obstacles presented by AR design development and application in the classroom, and second, the effectiveness of AR in achieving a better understanding of sustainability as a course topic. We also assessed the role of AR in improving learning outcomes specific to sustainability in the built environment though interdisciplinary collaboration between students from architecture and civil and mechanical engineering.
\end{abstract}

Keywords: Cyberlearning, STEM, virtual reality, sustainability

\section{Introduction}

According to the National Science Foundation cyber innovation is the process of developing nextgeneration cyberlearning approaches through high-risk, high-reward advances in computer and information science and engineering (NSF, 2017). The challenge to integrate technology into the STEM classroom started as early as the 1990s with computer application designed to be used by individuals with instructor support. These early explorations were designed as aids to the individual student. Recent work addresses the use of networked learning technologies where the learning approach is relational. Learning takes place in relation to others and to learning resources. Researchers believe the use of networked technologies provide affordances for learners to engage in such important cognitive and metacognitive processes as problem definition, information discrimination, reasoning and argumentation, solution negotiation and evaluation (Krippen \& Antonenko, 2017). And unlike earlier learning set-ups where individual learners had limited interaction with colleagues the new technologies using mixed reality (MR), immersive visualization experiences in Computer Augmented Virtual Environments (CAVEs), and large-scale tile walls, allow students to work collaboratively and cooperatively. Research indicates the use of effective and interpersonal communication promotes critical thinking and deep learning (Alias et al., 2017; Cartney, 2006; Fink, 2004; Springer, Stanne, \& Donovan, 1999; Kalaian \& Kasim, 2014). Our project addresses the use of a mixed reality technology — the Microsoft Hololens - in a collaborative learning environment in a STEM classroom.

In this paper we report our findings about the deployment of the augmented reality (AR) application in classroom innovation targeted to enhance STEM education. The overall project goals were: 1) explore opportunities and obstacles presented by the integration of immersive and simulation technologies in support of collaborative problem-solving, 2) examine the impact of various strategies to improve the effectiveness of these technologies through a formative design process, and 3) contribute to research on how people learn using technology-mediated environments by developing an understanding of the various attributes of these technologies. This paper focuses on the development of the AR application needed for the cyberlearning component of the study. 
The AR application was developed for the Microsoft HoloLens ${ }^{\mathrm{TM}}$ head-mounted display. ${ }^{1}$ It involved the development help of University of Arkansas Tesseract Center researchers and their expertise in developer content to design our AR-platform. Integrating AR with other simulation technologies promises to lead the next generation of computer-based learning environments.

Table 1. Terminology

\begin{tabular}{|c|c|}
\hline Mixed reality & $\begin{array}{l}\text { A general term used to indicate the use of a (typically) digital device creating a } \\
\text { virtual or simulated representation of either } 2 \text {-d or 3-d information. }\end{array}$ \\
\hline d Reality & $\begin{array}{l}\text { Augmented Reality (AR) is the ability to augment the real-world environment with } \\
\text { computer-generated information, experienced by multiple users in real time. In the } \\
\text { AR experience the user is aware of both the real-world condition and a virtual one } \\
\text { at the same time. For example, a museum visitor using headphones while viewing an } \\
\text { exhibit is augmenting their experience while still situationally aware. AR is by } \\
\text { definition also and MR experience }\end{array}$ \\
\hline Sustainability in $A E C$ & $\begin{array}{l}\text { The areas of focus with regard to sustainability in the building sciences are: } \\
\text { 1) Building Envelope, 2) HVAC and MEP 3) Life Cycle Analysis for all aspects of } \\
\text { building from design, fabrication to construction, maintenance and re-use, 4) Site, 5) } \\
\text { Energy, 6) Materials }\end{array}$ \\
\hline
\end{tabular}

\section{$1.1 \quad$ Research Questions}

As a result of the proliferating digital realm, classroom settings and learning dlesign are undergoing dramatic transformations and changes. While blackboard and chalk are replaced by the smart board and the stylus, the next evolution includes the logistics of augmented reality, suggesting students could wear mixed reality headsets like the HoloLens ${ }^{\mathrm{TM}}$ goggles to view an overlapping virtual and physical reality. This means displacing instruction from the classroom to the headset to allow for direct immersion and learning in the physical space under study. The mix of virtual and physical reality augments the information immediately available to students in the classroom as the graphic and alphanumeric data are directly brought together into a single setting. Because of this shift students better apprehend the significance of building drawings and digital models when mapped over a physical space. In our study we found an instructional phase was necessary to acquaint the students with the use of the technology and at the same time allow them to adjust to working with the headgear throughout the space (Figure 1). As a result we ended up teaching in both classroom and the study site.

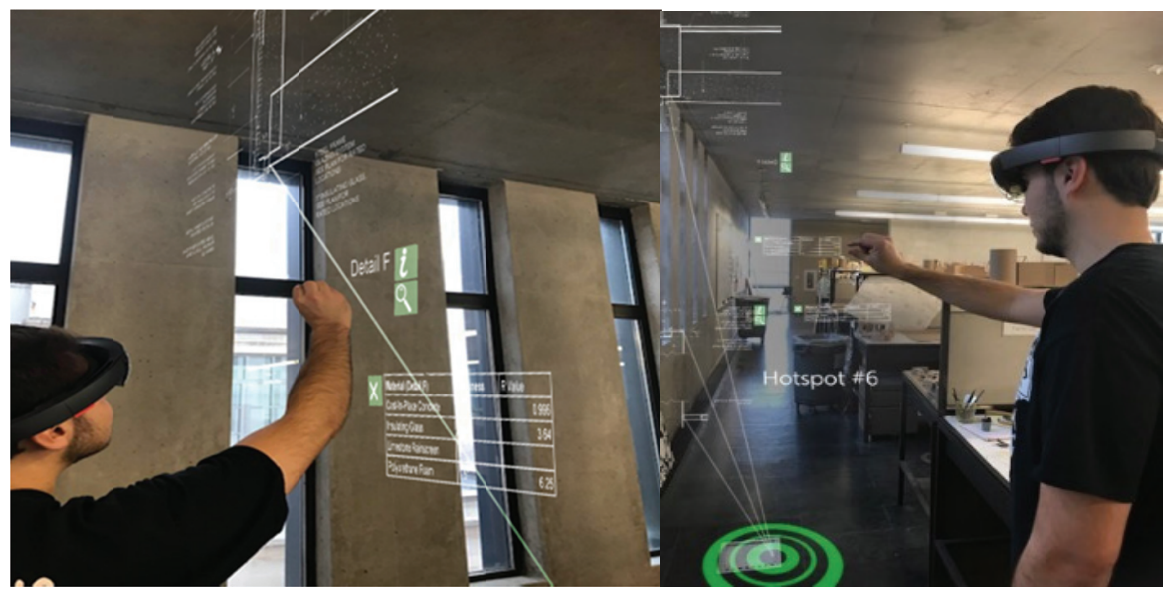

Figure 1. Student wearing HoloLens ${ }^{\mathrm{TM}}$ head mounted display

\footnotetext{
${ }^{1}$ The Development Edition of the Microsoft HoloLens was introduced on the market in 2016. HoloLens runs the Windows Mixed Reality platform under the Windows 10 operating system. The HoloLens usies on-board computing.
} 


\subsection{Development of the AR approach}

The UA team assumed the use of the Microsoft HoloLens ${ }^{\mathrm{TM}}$ head-mounted display (HMD) based on our belief it would be reasonable in the study timeframe to develop content for this device. The HoloLens is equipped with depth-sensing cameras, holographic lenses and computer processors to create a blended environment where the user can view reality while also "seeing" overlaid holographic data. This allows the user to interact with digital content as part of the real world. By overlaying these images on reality, students were able to "see" the different components of the building while standing in the building space. Based on our experimental data the formative evaluation informed refinements in the approach to the development of content for the HoloLens ${ }^{\mathrm{TM}}$. Students from our previous year's control group said they became overwhelmed trying to work through too large an area in the building while managing quantitative analysis for three systems; we therefore decided to focused on a single classroom area - a large studio located in Vol Walker Hall on campus for the experimental group using the AR application. We collaborated with the University of Arkansas Tesseract Center for Immersive Environments on the design of the content application. The content development of the digital information in the HoloLens ${ }^{\mathrm{TM}}$ by researchers at Tesseract consisted of creating an immersive application that indexes, calibrates, and displays educational graphic and alphanumeric data on top of the physical space under consideration using previously generated Building Information Modeling (BIM) for the design and construction documents.

As indicated above the space investigated for the problems sets in the course was limited to a single classroom area: a large studio located on the south side of the $3^{\text {rd }}$ floor of Vol Walker Hall. Vol Walker Hall (VWH) and its new extension to the Stephen L. Anderson design Center (SLADC), is located on the University of Arkansas campus. The southern studio in the $3^{\text {rd }}$ story of SLADC was the specific area we used for the technical problem sets given to students in the course and the locale for the AR test. Figure 2 (a) shows the plan of the space and the red dot location for the HoloLens ${ }^{\mathrm{TM}}$ spatial calibration to the physical space. Green arrows indicate the path taken by the user to walk through the studio space. Green dots specify the locations at which the user can stop and retrieve 2- and 3-d information in the AR-application consisting of digital detail drawings, diagrams, and tables. The tables contain data describing the thermal characteristics of the current materials, the mix and the structural properties of concrete used in the building. Diagrams also provide context and acquaint the student with the logic of the overall structural, lighting and HVAC systems. In short, all just-in-time information useful to the student is stored in each of the green dot locations.

\section{Teaching Sustainability using AR}

The new teaching and learning environment using integrated BIM (Revit) with augmented reality (AR) provides three-dimensional, interactive, annotated models of buildings for visual learning. In establishing how to evaluate the influence of AR on student learning, interdisciplinary courses were leveraged between architecture, mechanical, and civil engineering (Figure 3). Faculty collaborated to teach a joint course offered as an elective in all three disciplines on advanced topics in sustainability. We expected that a given student in each discipline would lead their team members and encourage their contribution for the assignments related to her/his field of study. For instance, when the assignment was about building structure the civil engineering students took the lead in working on the assignment. The teaching staff believed sustainability is an area with adequate duplication in all three disciplines for meaningful content to be created for a shared course. Assignments included sustainability factors relating to the site, building envelope, mechanical systems and structures as fertile domains for the study of sustainability.

For the content development of the digital information in the HoloLens ${ }^{\mathrm{TM}}$ the team collaborated with the UA Tesseract Center using previously generated BIM information and drawings from Vol Walker Hall/Stephen L. Anderson Design Center. Tesseract researchers were given a set of BIM (Revit) drawings of the building, including plans, sections, details and 3D model. We then collectively determined the appropriate physical locations in the 3rd floor space where students could retrieve relevant information such as 2-d drawings and other 2-d or tabular data. The team conceived the application and platform like a museum exhibit, where information appears near pertinent building features as shown in later figures in this paper. 
The program logic, organization and hierarchy of the various elements include three layers of information: 1) physical space, 2) the Revit model and 3) overlaid information (Figure 4).

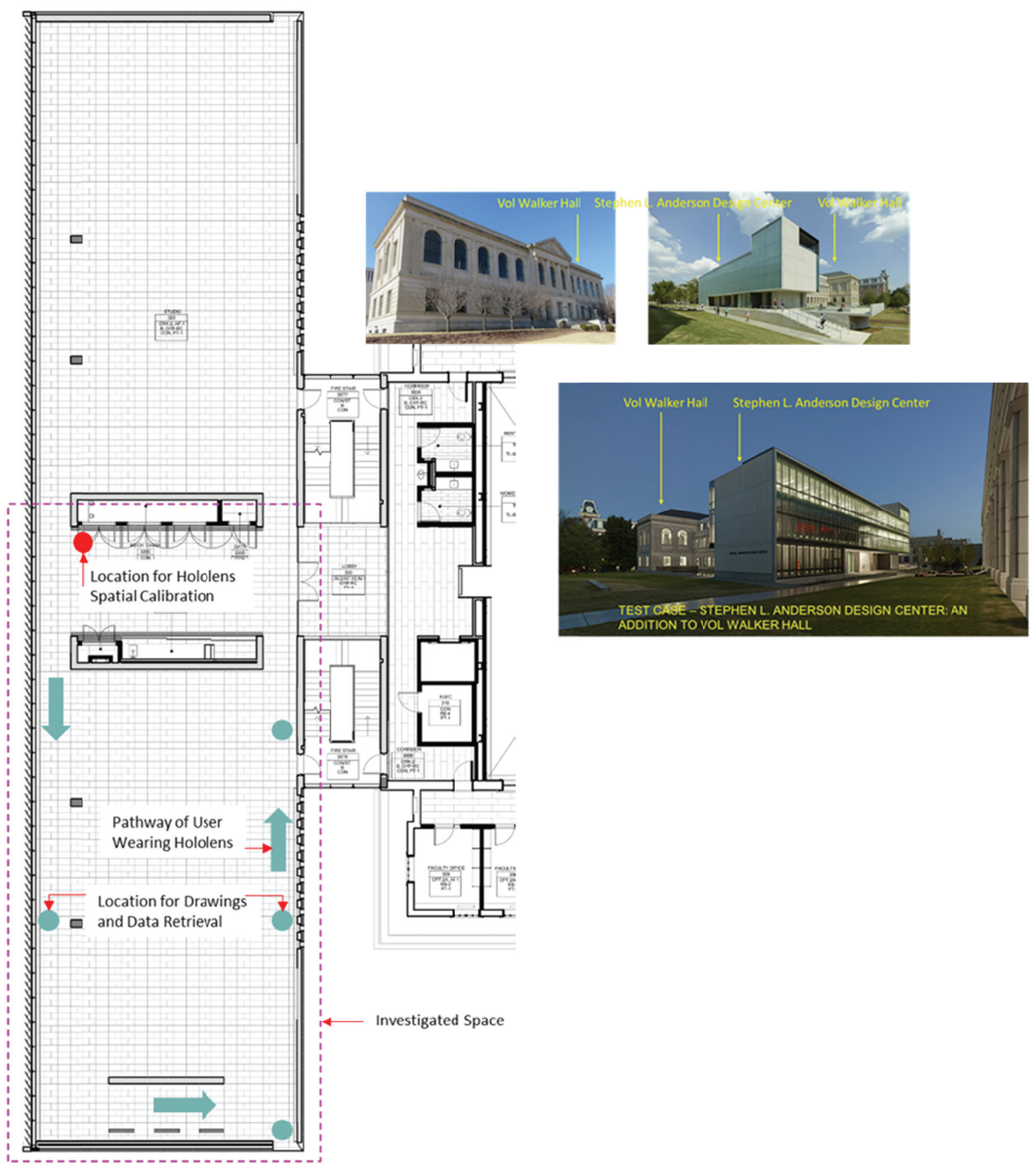

Figure 2. (a) Test case studio in 3rd floor plan of SLADC (b) and (c) View of VWH and SLADC

Working with the Tesseract we decided to use Unity 3D game engine to create the interactive experience within the HoloLens ${ }^{\mathrm{TM}}$. Unity 3D has an easy-to-use graphical interface and allows for the development of code to control the display of $2 \mathrm{D}$ and $3 \mathrm{D}$ models in order to create digital experiences. It also facilitates output to many different technologies, including phones, virtual reality headsets, tablets, and computers, and most importantly for this project, the HoloLens ${ }^{\mathrm{TM}}$. Out of only a few available AR platforms, HoloLens ${ }^{\mathrm{TM}}$ was chosen for its portability and immersion, since it is a head mounted display, like a visor, which projects translucent, digital images onto a clear optical surface in front of the user's eyes. 



Figure 3. Team collaboration in sustainability between architecture, civil and mechanicall engineering students

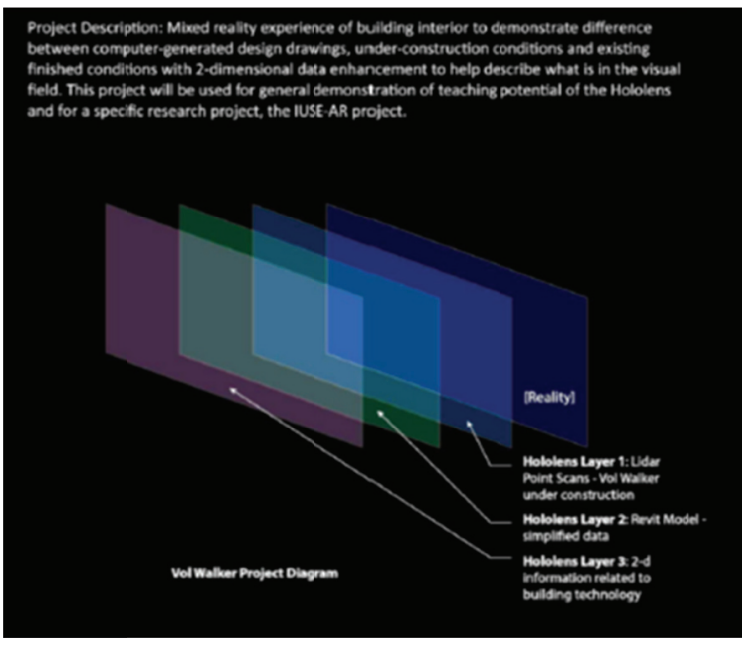

\begin{tabular}{|c|c|c|}
\hline 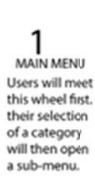 & (E) $\mathrm{S}$ & 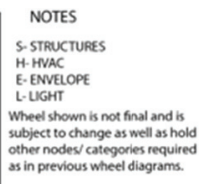 \\
\hline 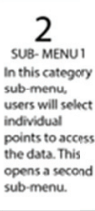 & (S) $\rightarrow \stackrel{50010}{\circ} \stackrel{5002}{\bigcirc} \cdots .$. & 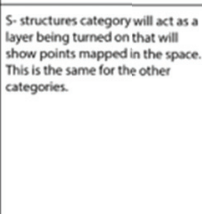 \\
\hline 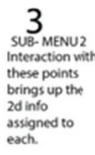 & $\stackrel{5001}{O} \rightarrow$ & 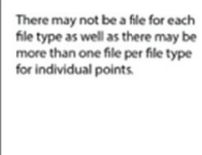 \\
\hline
\end{tabular}

Figure 4. Flow chart expressing the 3 layers organization and data flow structure as programmed via C\#.

Unity's 3D editor capabilities allowed Tesseract to overlay the provided drawings and 3D models onto an exported Revit model of the test space in Vol Walker Hall, then facilitated the input of interactions using the programming language $\mathrm{C} \#$ for accessing the drawings, diagrams and data within the 
HoloLens $^{\mathrm{TM}}$. After the application is packaged in Unity, downloaded onto the HoloLens ${ }^{\mathrm{TM}}$ (Figure 5b), then opened by a student, the Revit model of the space (Figure 5a) is removed, leaving the actual 3rd floor physical space in the SLADC as the backdrop of the experience. To use the application, students turn the HoloLens ${ }^{\mathrm{TM}}$ on, place it on their head, select the application from the icons projected in front of them (Figure 5b), then follow a short alignment process once the program has loaded. After the alignment completes, the application displays a default path prompting the use to call-up educational overlays (holographic drawings, diagrams and alphanumeric data). Most interactions can be viewed without any further input from the user, but if more information is needed, the HoloLens ${ }^{\mathrm{TM}}$ platform allows the execution of verbal and physical commands to retrieve the holographic diagrams, details and data.
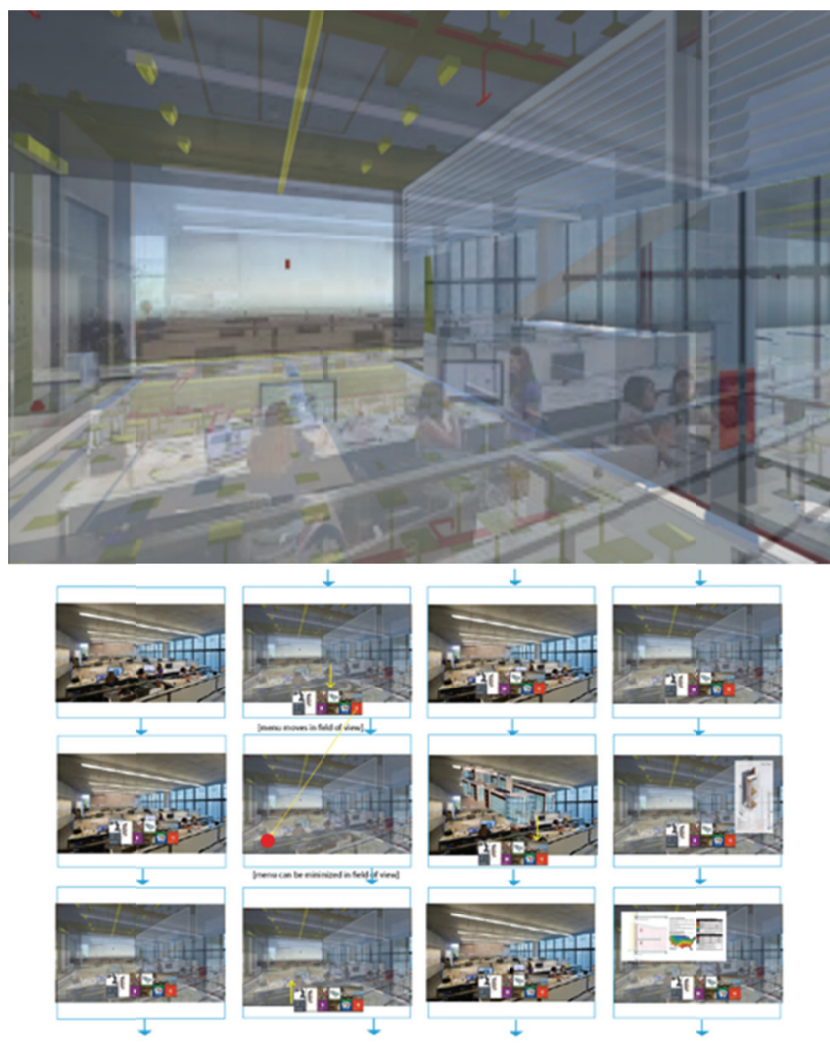

Frames w/Bar-Menu Interface W. Wholoview Propect_ua UuSE

Figure 5. (a) Simulated view- HoloLens ${ }^{\mathrm{TM}}$ showing projection of Revit model on top of actual physical space, (b) Frames with bar menu interface.

The initialization of the application and calibration of the walkthrough through studio occurs at a specific location shown as a red dot in Figure 2a. As the diagram in Figure 6 shows, the user can toggle between the various path displays which include the building envelope, HVAC and structural systems.

Walking through the space while wearing the HoloLens ${ }^{\mathrm{TM}}$ and running the Vol Walker Hall application users can spot green or red dots and arrows indicating a path to follow and the locations of drawings, diagrams and data. In addition to viewing the drawings in-situ, the user can decide to finger "pinch" the "magnify" icon to enlarge a drawing, or "pinch" the "information" icon for tables containing materials specifications, thickness, and R-value. Such tables help students understand the materials description and characteristics, their layering and consideration in heating and cooling load calculations, and propose, where necessary, different envelope configurations to reduce the energy consumption in the building (Figures $7,8,9,10$.) 


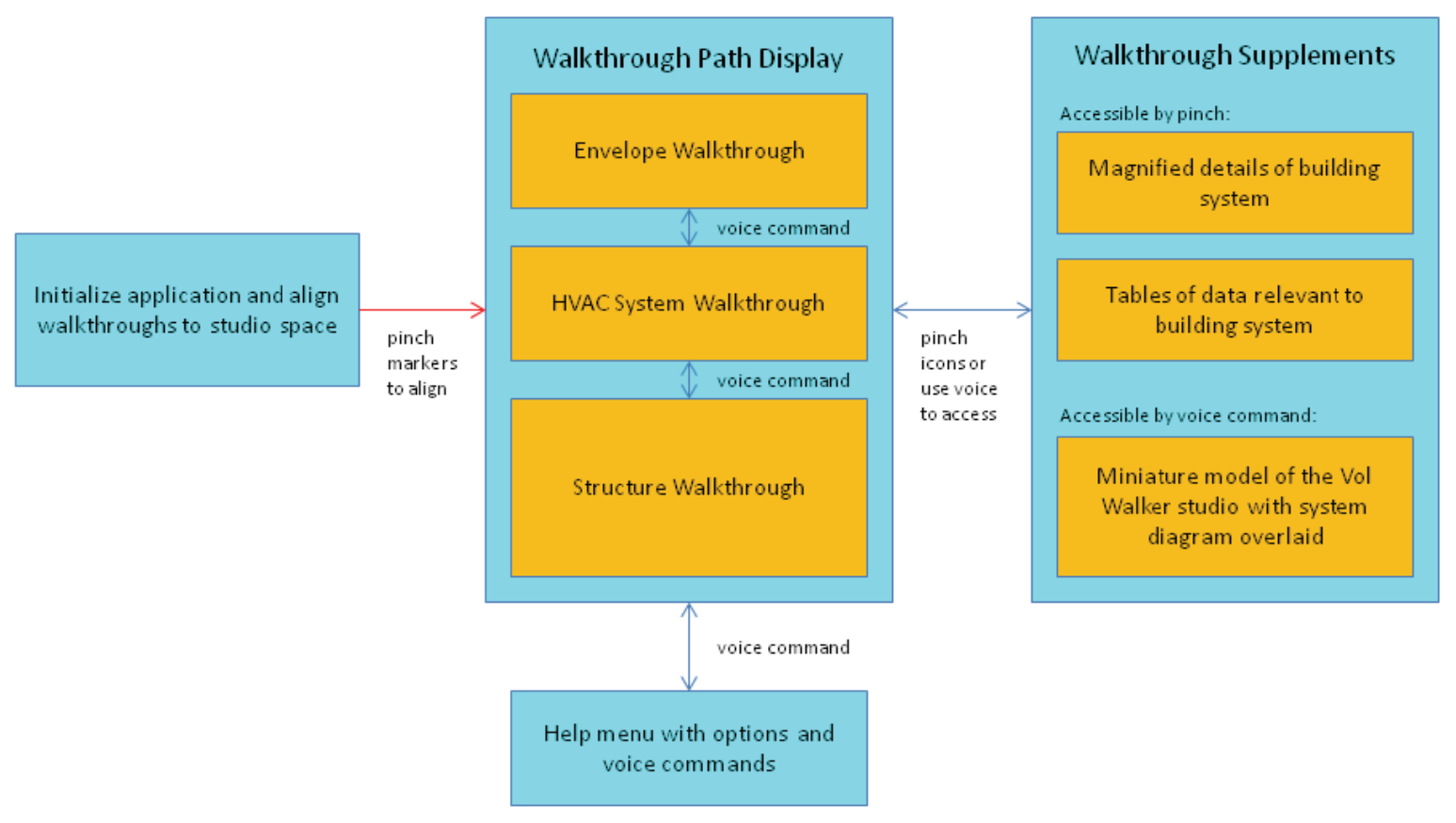

Figure 6. Interaction paths inside VWH/SLADC HoloLens ${ }^{\mathrm{TM}}$ application.

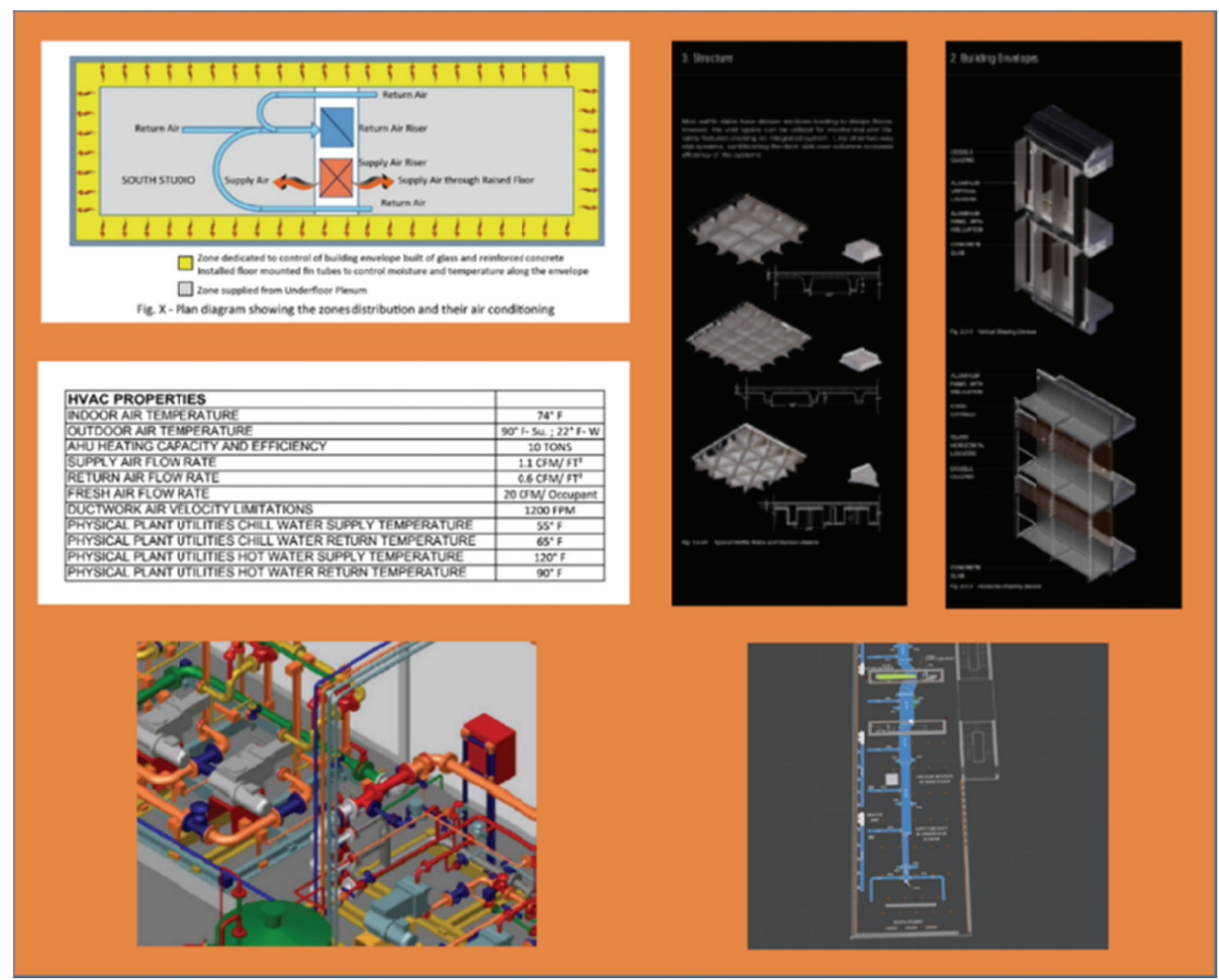

Figure 7. Display in HoloLens ${ }^{\mathrm{TM}}$ of table with HVAC data; diagram layout, plan \& 3D view of HVAC and details 


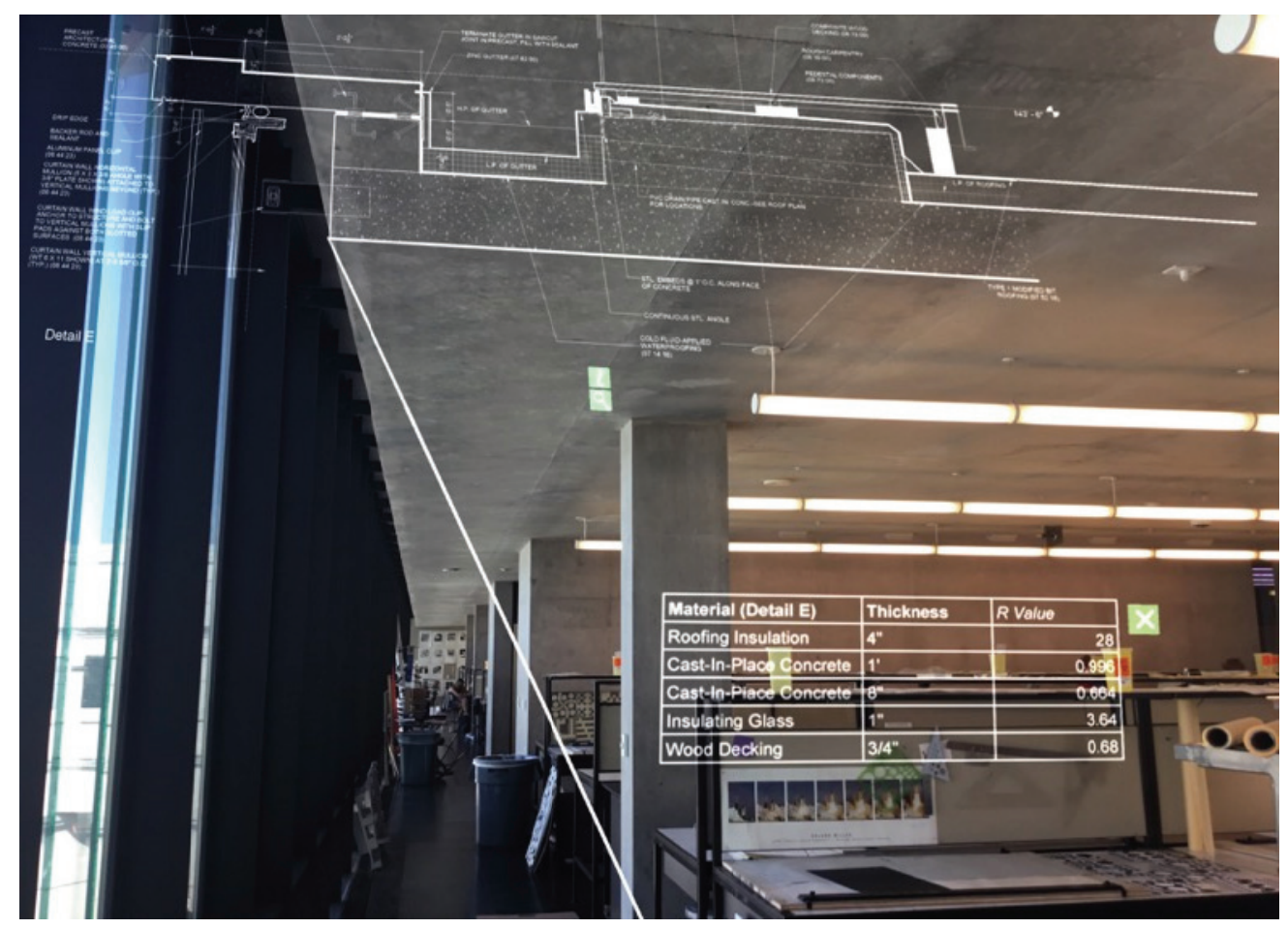

Figure 8. In-situ roof detail with table of R-values

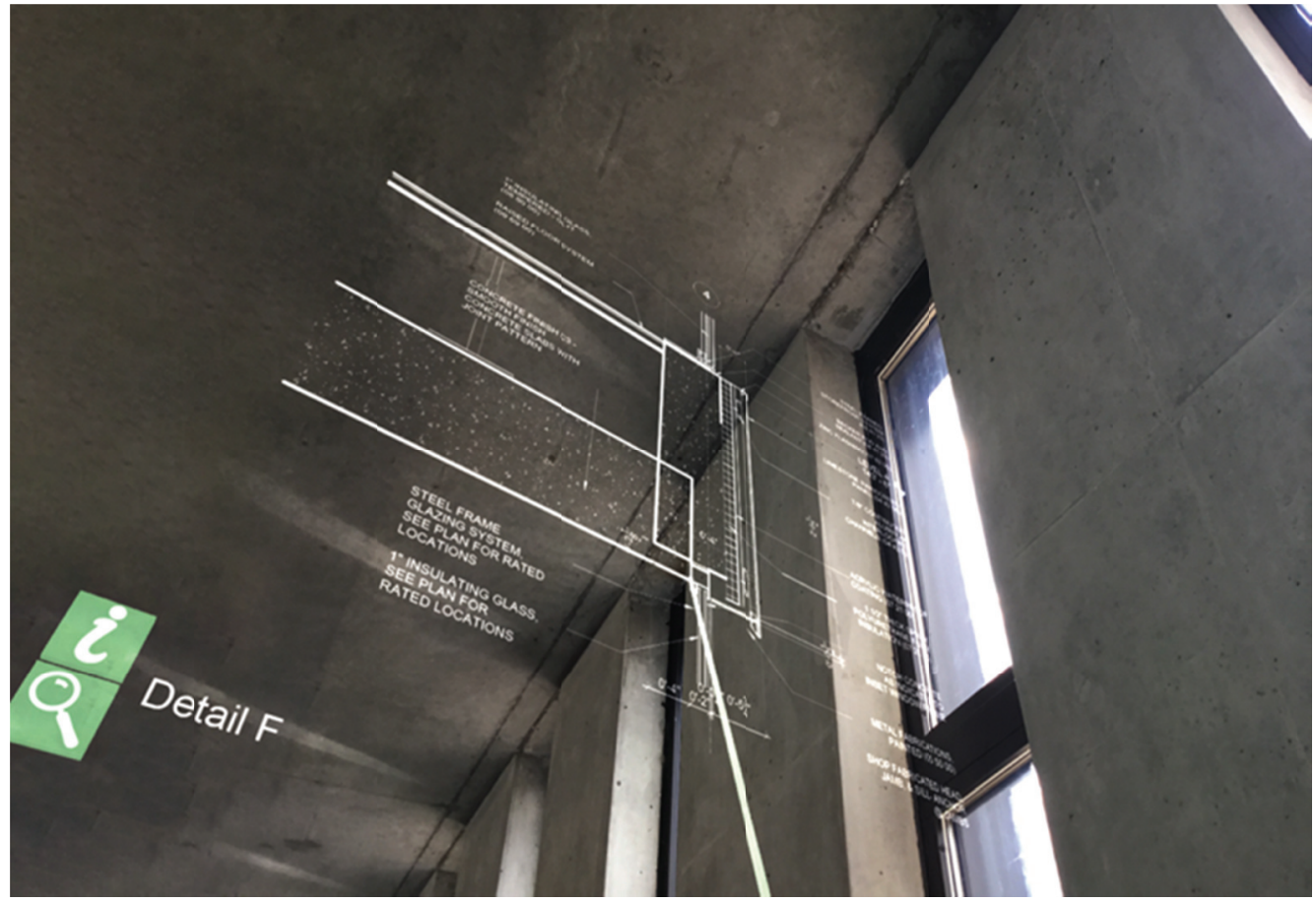

Figure 9. In-situ roof-wall detail with associated icons

The application provides the user with display information about three specific domains in the building: envelope, HVAC systems, and structure. The user can use a voice commands, i.e., "show envelope, show mechanical, show structure" to toggle between these three domains. 


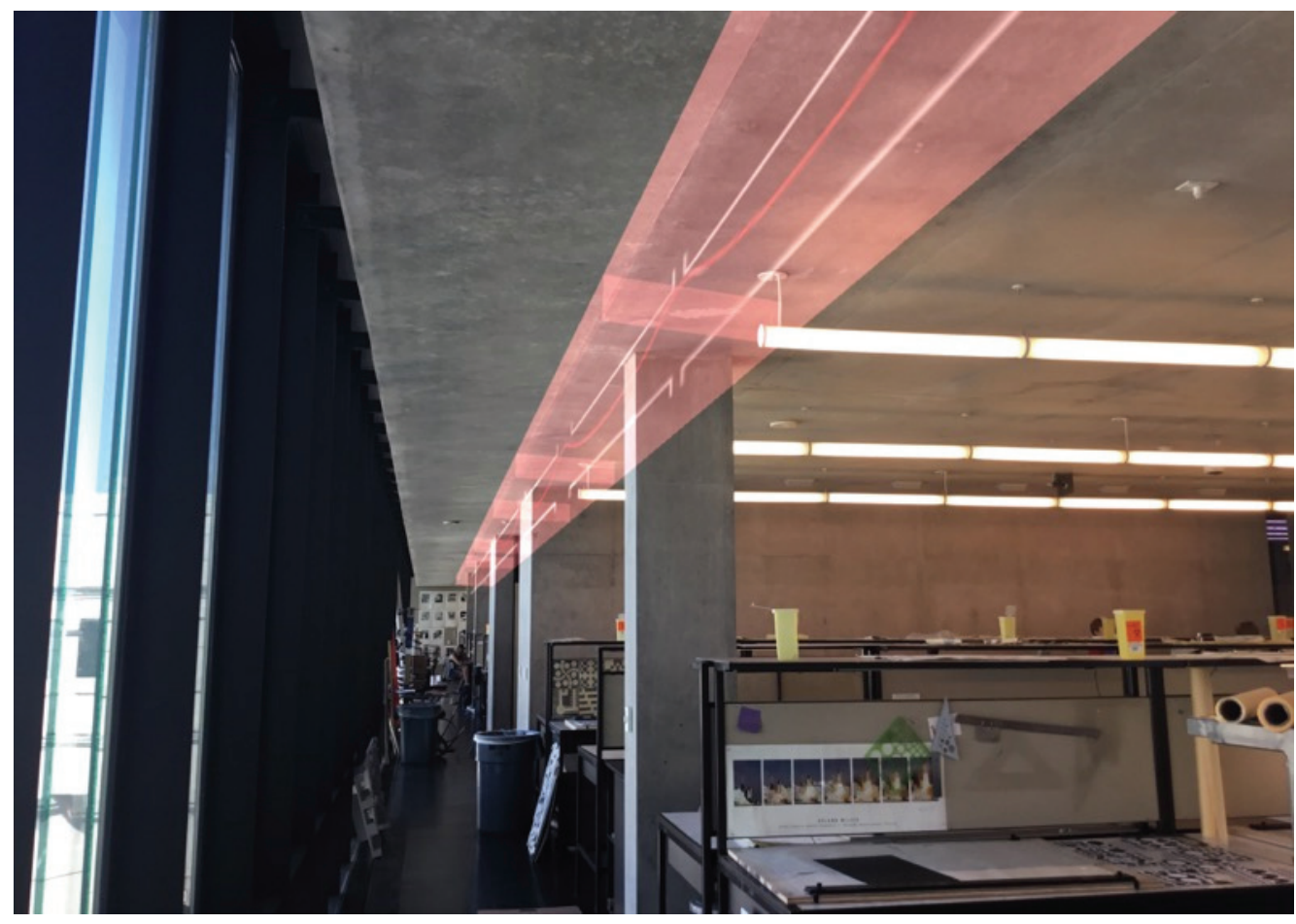

Figure 10. In-situ structural stress diagram

If the users wish to see locations of all available details, as well as the overall diagram of the envelope, HVAC system, or structure (depending on the domain), the user can issue a command to the HoloLens ${ }^{\mathrm{TM}}$ to display a small model of the studio space with overlaid diagrams, as shown in figures 11, 12 and 13 .

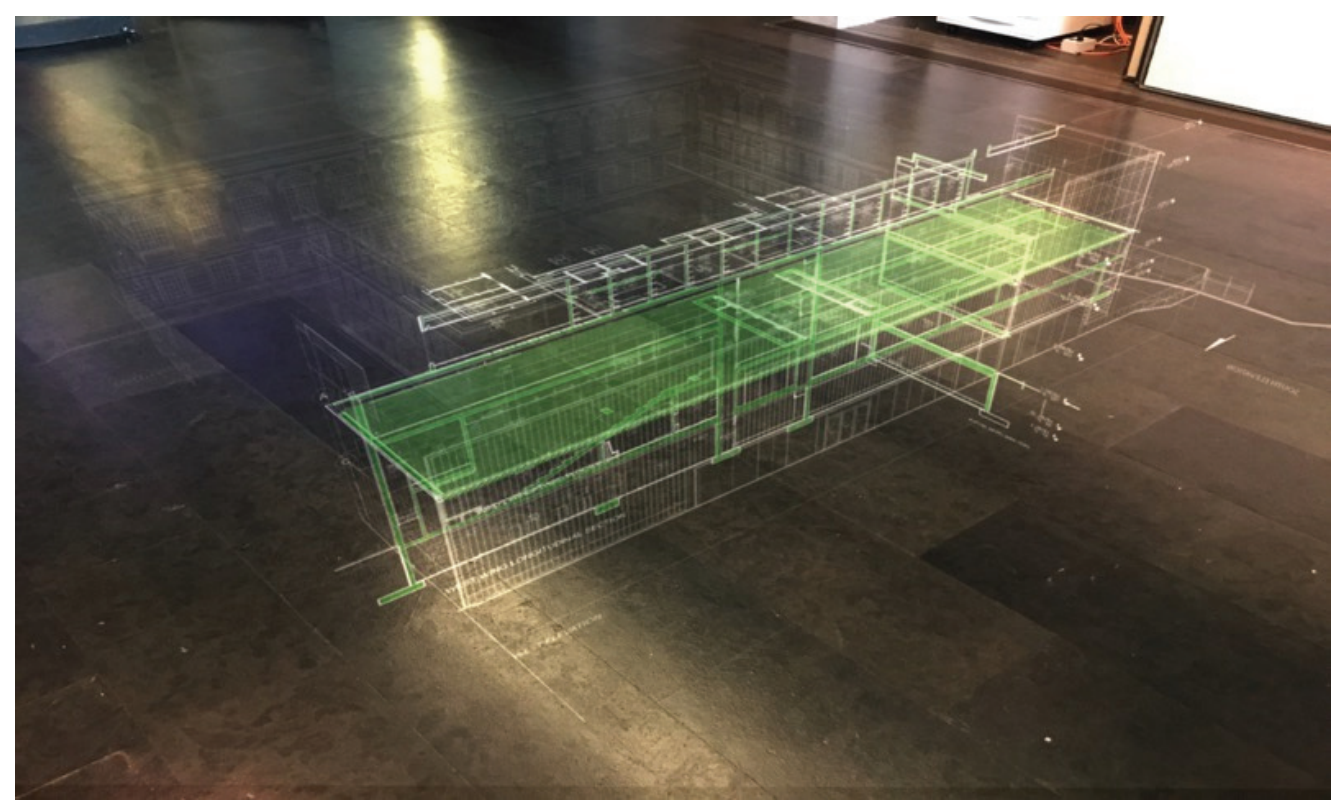

Figure 11. Orientation diagram (envelope mode) that can be summoned at any location. 


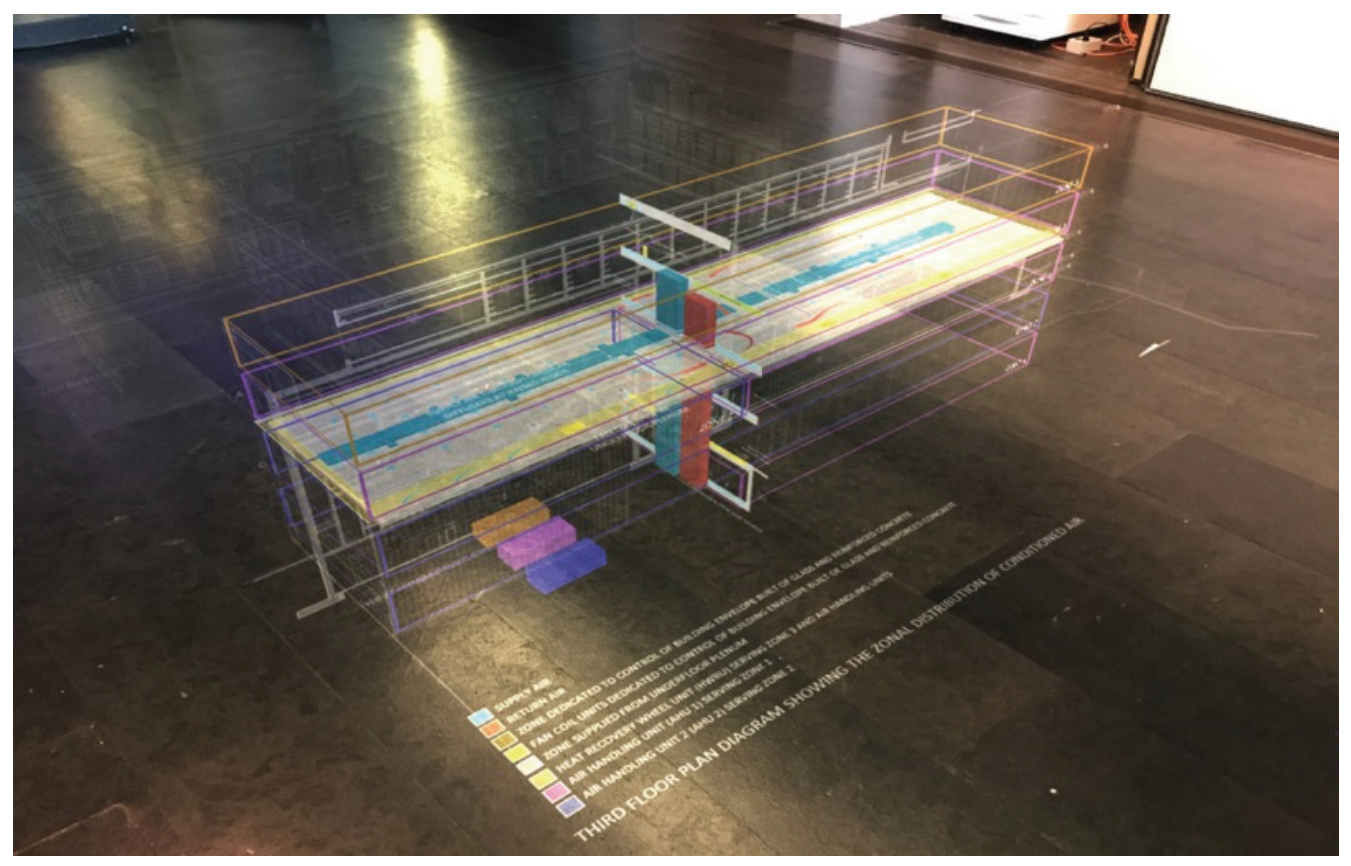

Figure 12. Orientation diagram (HVAC mode) that can be summoned at any location.

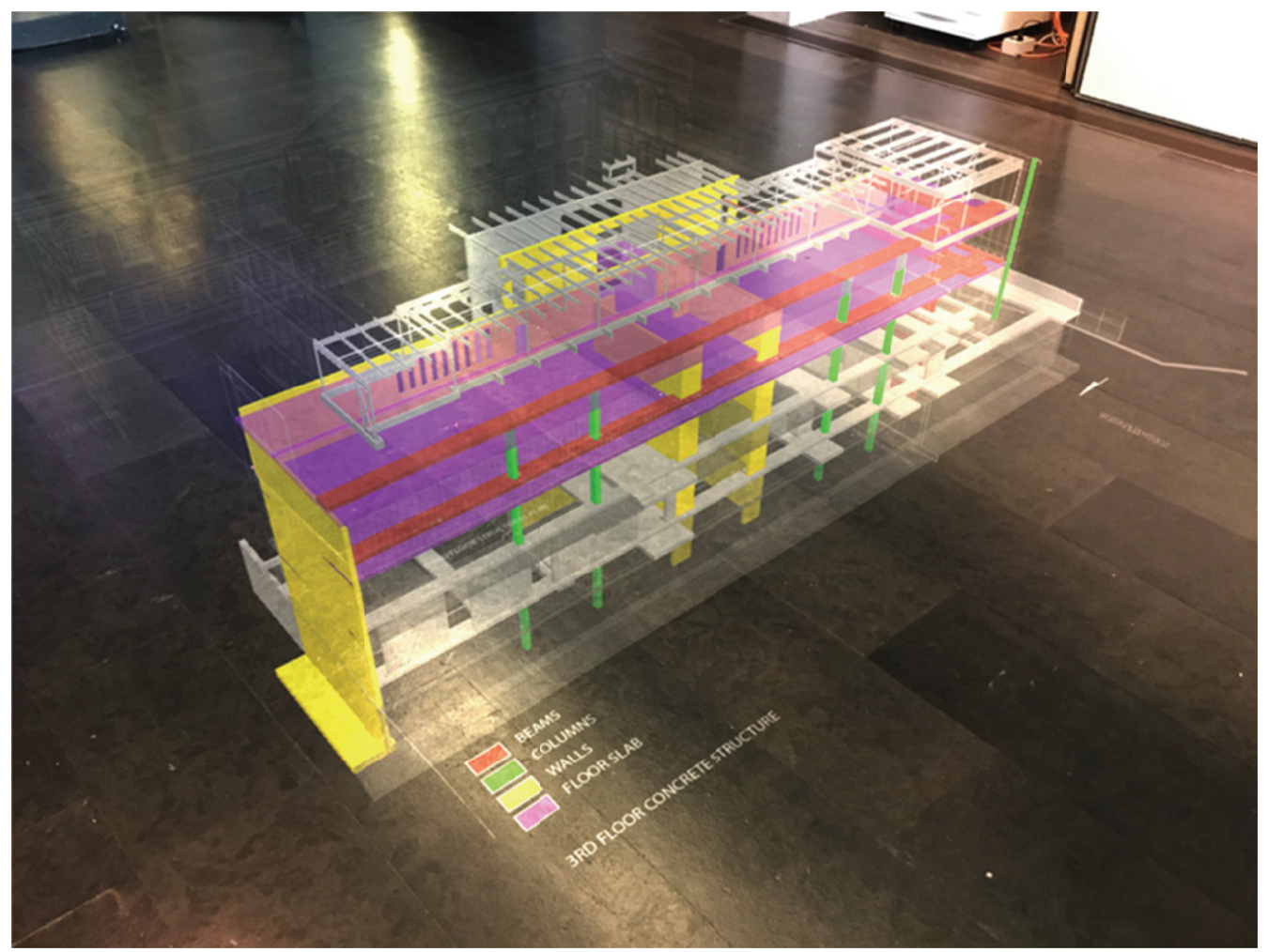

Figure 13. Orientational studio diagram (structure mode) that can be summoned at any location

\section{$3 \quad$ Results}

The entire synchronization, between HoloLens ${ }^{\mathrm{TM}}$, drawings, diagrams, and walkthroughs are a complex phase of work deserving additional explanation. The calibration of the diagrams and details onto their 
exact locations within Vol Walker had issues due to the technical constraints of the spatial recognition of the Microsoft HoloLens ${ }^{\mathrm{TM}}$ technology. However, the walkthrough, drawings retrieval, and calibration did work well enough to build confidence in the application with some modification. For ease and effective use of the AR applications, the tream decided future additions would include 1) a larger database of drawings and diagrams, 2) improvements to the design of the interactions with enhanced and simplified calibration through new technology or new methods of development. Additionally, a voiceover could be recorded and played within the space to better tutor studentts on how to use the application or to explain what they are seeing within the head mounted display.

This first trial run led to several discoveries regarding the merits of AR. Students appreciated the ability to have the in-situ radioscopy of a building's construction and structural details as described by the overlapped drawings. For many of them it was the first time they were able to associate drawings together with their actual physical conditions as they learned about the assembly of the building materials. Overlaid window details at the knee wall were quite revealing about the seals from water and humidity penetration. This was an important insight for the faculty. It overturned some of our assumptions about student ability to make reasonable connections between drawings and physical applications.

The aforementioned improvements could be made to effectively achieve better collaboration among the team members as they use the HoloLens AR program. As for the course organization, in the next round we plan to have the three courses scheduled for the same time period. This way, students do not need to go out of their way to make meetings possible.

\section{Future Research}

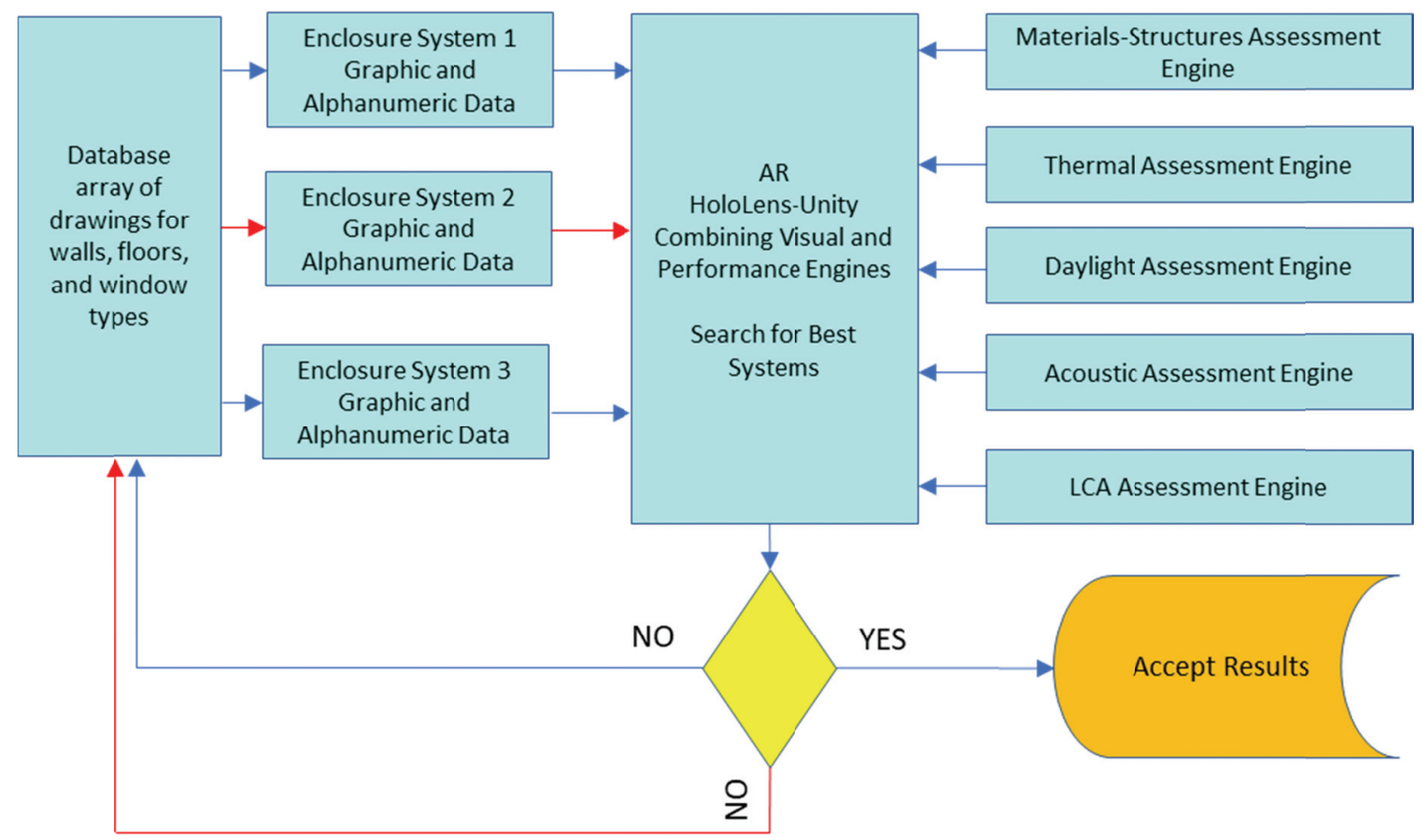

Figure 14. Flowchart describing the incorporation of visual and performative systems in buildings.

While we are pleased with the inherent relevancy of AR as a teaching tool, the next phase will be focused on achieving better resolution and functionality of AR within the entire system. In the end this hyper visual system helped students better appreciate the technology involved in the assembly of building envelopes, the floor-envelope or roof envelope connections, HVAC systems integration, as well as the glazed windows incorporation. A key component of the approach was providing just-in-time, informative feedback to the groups regarding their collaborative efforts, comments on their questions 
with respect to the Technical Report, as well as timely process-based evaluations and subsequent process changes that help improve group interactions and collaborative learning.

Based on our results from the experiment discussed here the research team plans to rally the visual with the performative for next steps. In other words, students should not only understand the layout and agency of the various building components and systems, but also proceed with the opportunities provided to contrast and compare the performance inherent in various systems (envelope, lighting, acoustics, HVAC systems, site, etc.).

Our flowchart describes the visual and performance aspects of the building (Figure 14). The former explains the layout of the various components and systems, and the latter assesses the performance of the various building components and systems such as enclosure, which also allows the retrieval of subsystems such as floor-envelope, slab-on-grade-envelope, and others

This protocol targets the education of students enrolled in architecture, engineering and related AEC disciplines. Effective learning using this approach relies on the assessment of existing buildings through collaboration between students from architecture and engineering. Hence, students learn from successes or failures of existing and recently built buildings, specifically those that have received recognition through certification. The need to further improve problem-solving and collaborative learning skills of Architecture, Civil, Construction and Mechanical Engineering students will further lead to the design of more sustainable and better performing buildings.

Acknowledgements. The work described in this paper was partially supported by the National Science Foundation under award No.1504898. The HoloLens-AR development work is underway at the Tesseract Center at the University of Arkansas under the direction of Dr. David Fredrick with Keenan Chet Cole, Chloe Costello and undergraduate Corey Booth. Documentation of the Vol Walker construction was done by the Center for Advanced Spatial Technologies (CAST) at the University of Arkansas.

\section{References}

1. N. A. Alias, J. E. Luaran, and S. A. Kalaian. Pedagogical Approaches for the 21st Century Student-Driven Learning in STEM Classrooms, pages 72-86. IGI Global, Hershey, PA, USA, 2017.

2. P. Cartney and A. Rouse. The emotional impact of learning in small groups: highlighting the impact on student progression and retention. Teaching in Higher Education, 11(1):79-91, 2006.

3. K. J. Crippen and P. D. Antonenko. Designing for Collaborative Problem Solving in STEM Cyberlearning, pages 89-116. Springer International Publishing, Cham, 2018.

4. Kalaian, S. A., \& Kasim, R. M. (2014). A Meta-analytic Review of Studies of the Effectiveness of Small-Group Learning Methods on Statistics Achievement. Journal of Statistics Education, 22(1). Available Online at www.amstat.org/publications/jse/v22n1/kalaian.pdf

5. N. Rania, S. Rebora, and L. Migliorini. Team-based learning: Enhancing academic performance of psychology students. Procedia - Social and Behavioral Sciences, 174:946 - 951, 2015. International Conference on New Horizons in Education, INTE 2014, 25-27 June 2014, Paris, France.

6. A. Repenning, A. Basawapatna, and M. Klymkowsky. Making educational games that work in the class- room: A new approach for integrating stem simulations. In 2013 IEEE International Games Innovation Conference (IGIC), pages 228-235, Sep. 2013.

7. L. Springer, M. E. Stanne, and S. S. Donovan. Effects of small-group learning on undergraduates in science, mathematics, engineering, and technology: A meta-analysis. Review of Educational Research, 69(1):21-51, 2019/03/10 1999 . 